\title{
Locating approach and building layout design for "sandwich class housing" in Wuhan City
}

\author{
Hong $X U^{1, a}$ \\ ${ }^{1}$ College of Urban Construction \\ Wuhan University of Science and Technology \\ Wuhan, China \\ axuhong@wust.edu.cn
}

\begin{abstract}
Keywords: sandwich class housing; locating problem; building layout design.
Abstract. "Sandwich class housing" is an emergent social problem in most cities of China. Where to locate the public housing for sandwich class and what kinds of building layout fit into the needs of sandwich class are two basic questions to local governments. This paper proposed a locating approach of sandwich class housing through analytic hierarchy process method, which considers the influence of income, distance, time total money cost, school, hospital, store, neighborhood on the choosing of housing locations. As result, 9 candidate locations were chosen as the housing location for sandwich class in Wuhan city. Also, this paper presents some building layout design plans for meeting the needs of sandwich class livings. They can be categorized as diverse, changeable and detailed layout designs. The feature and satisfied functions of these categories were discussed in this paper. Both works can provide a suggestion for local government to make decisions of building public housing for sandwich class.
\end{abstract}

\section{Introduction}

"Sandwich class" in China mainland refers to people who do not have a qualification of buying affordable housing and price-fixed housing [1-5], and they cannot afford commercial housing under the constraint of their income. Most of them are usually graduated university students and off-farm workers[6, 7]. Under the housing scheme in China, high-income class can buy commercial housing and the low-income class can rent public housing. So the "Sandwich class" between the high-income and low-income class is in the middle or below the middle class. Their housing problem is very important for a harmonious society[8-9]. However, for local government, there are two critical questions to provide housing for sandwich class, where the best location to busing house for them are and what the best building layout plan for meeting the household needs of them. The two questions should be taken into account seriously within their housing scheme. Section 2 discusses the current problems of housing scheme for sandwich class, section 3 introduces the location analysis of affordable housing for sandwich class, section 4 introduces building layout design and function analysis, and the last section conclude this paper and introduce some future works.

\section{Current problems of housing for sandwich class in Wuhan city}

In 2002, Wuhan set up a plan of providing affordable housing and price-fixed housing for low-income class through three approaches, rent subsidies, affordable housing and price-fixed housing. Due to the benefit of this plan, there are 20,000 families can have their house or apartments. Current years, Wuhan try to built 200,000 houses with $10,000,000 \mathrm{~m} 2$ area to provide affordable housing for low-income families. The policy of applying these housing only limit to the families with $10 \mathrm{~m} 2 /$ person. Therefore, there are much more families can neither buy their commercial house nor rent affordable housing beyond the limitations. In 2011, Wuhan government released a proposal to provide affordable housing for sandwich class. In this plan, the government will provide land to build housing with fixed housing area and price for sandwich class. It is a good plan for sandwich class. 
Obviously, the building of affordable housing for sandwich class should not be same as the previous affordable housing and price-fixed housing for low-income class in Wuhan, because the sandwich class always have more persons in a family including themselves, the older and the children[10-12]. There are two important aspects of providing housing for them, the location of buildings and the interior layout of hosing. The building locations should be near to the facilities such as school, hospital and shopping center. However, most of these locations were already used to commercial housing or office buildings. The layout of housing also should meet the requirement of people in three or four generations. Previous selection policy of affordable housing focuses on the built house. There are some inconveniences for sandwich if their houses were located in these same area. Therefore, it is urgent for government to choose suitable locations for sandwich housing and provide functional layout for sandwich class.

\section{The location analysis of affordable housing for sandwich class}

Location of public housing is very important to sandwich class, because that the attractive of these public rental is dependent on the convenience of the location with the consideration of transportation time costs, access costs, and the location neighorhood areas. The Wuhan Nanhu village and Mahu village area is an example for building public rental for sandwich class. Under the affordable housing task of local government, Wuhan wanted to build up 111,700 housing for low-income people, Hongshan district of Wuhan city need to build up 18,246 housing which is about 1/6 of Wuhan city's task. Plenty of idle apartment in Hongshan district make it to be chosen as the first testing area for providing affordable housing. However, 9,000 provided housing only attract 317 people to apply their housing, and finally only 210 people rented their housing. The reason for this phenomenon is caused by much factors such location, policies. However, location has much relationship of this phenomenon due to the reason that although Nanhu and Mahu village is located in city, but there are very few facilities for them to use, there are no good transportation and living infrastructure for them to use, no industrials to provide jobs for them. Another reason is the rental housing locations in Hongshan district is concentrated on a small area, much people have to give the application due to reason of job and family living. Therefore, the location of public housing is very important for potential applicants.

This paper use the analytic hierarchy process (AHP) $[13,14]$ to solve the chosen problem of public housing for sandwich class. There are four important steps of AHP, which are introduced as follows: (1). Building a systematical and hierarchical structure model

Figure 1 illustrates the hierarchical structure model to select the location of sandwich class housing. The middle layer include income, distance, time total money cost, school, hospital, store, neighborhood. There are 36 candidate locations in the last layer.

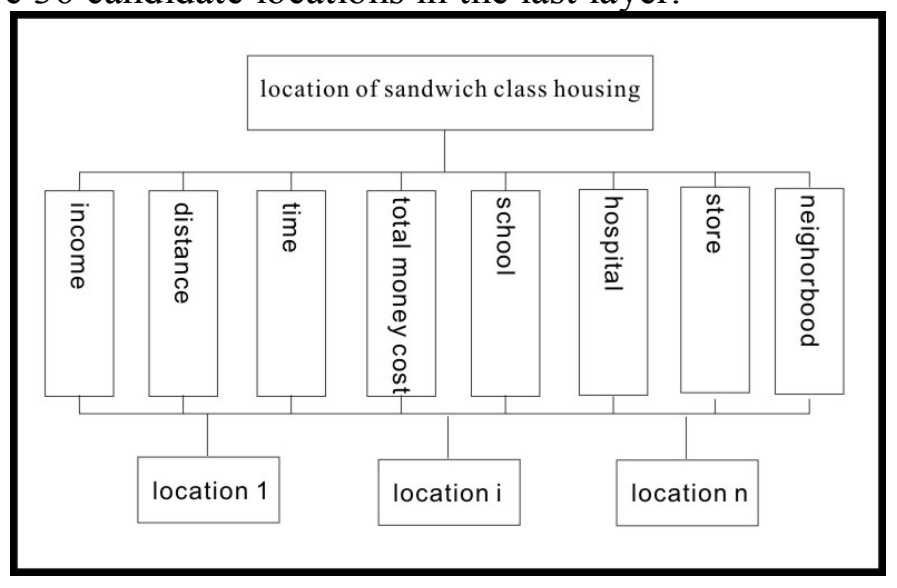

Figure .1 proposed hierarchical model

(2). Constructing comparison matrix 
The weight of above factors are important to the final selection. Usually, the weight $a_{i j}$ is defined in equ.(1) to reflect the importance of a factor ${ }^{i}$ when comparing it with factor ${ }^{j}$.

$$
a_{i j}=\left\{\begin{array}{cc}
1 & \text { same } \\
3 & \text { more } \\
5 & \text { better } \\
7 & \text { much_more } \\
9 & \text { most } \\
2 n & \text { between } \\
1 / n & n=1,2, \ldots, 9
\end{array}\right.
$$

The comparison matrix is defined as follows:

$$
A=\left(\begin{array}{cccccccc}
1 & 9 & 5 & 9 & 7 & 7 & 3 & 3 \\
1 / 9 & 1 & 3 & 3 & 3 & 5 & 3 & 3 \\
1 / 5 & 1 / 3 & 1 & 1 / 3 & 1 / 5 & 1 / 5 & 1 / 3 & 1 / 5 \\
1 / 9 & 1 / 3 & 3 & 1 & 7 & 7 & 5 & 3 \\
1 / 7 & 1 / 3 & 5 & 1 / 7 & 1 & 1 & 1 & 1 / 3 \\
1 / 7 & 1 / 5 & 5 & 1 / 7 & 1 & 1 & 5 & 7 \\
1 / 3 & 1 / 3 & 3 & 1 / 5 & 1 & 1 / 5 & 1 & 3 \\
1 / 3 & 1 / 3 & 5 & 1 / 3 & 3 & 1 / 7 & 1 / 3 & 1
\end{array}\right)
$$

(3). Consistency test

For test the consistency of the matrix $A$, consistency index is usually used as follows:

$$
C I=\left(\lambda_{\max }(A)-n\right) /(n-1)
$$

The consistency ratio $C R$ is calculated as:

$$
C R=C I / R I
$$

where $R I$ is the consistency criteria.

In this paper, $\lambda_{\max }(A)=8.627, C I=(8.627-8) / 7=0.089$. Therefore, this comparison matrix $A$ is acceptable.

(4). Sorting and decisions

To choose the housing locations, this paper sorted all candidate locations in Figure 2 according to the following approach:

$$
\begin{aligned}
& w_{x 1}=\left(w_{x 1,1}, w_{x 1,2}, \ldots, w_{x 1,8}\right)^{z} \\
& \ldots \ldots . . \\
& w_{x n}=\left(w_{x n, 1}, w_{x n, 2}, \ldots, w_{x n, 8}\right)^{z}
\end{aligned}
$$

and

$$
w_{z}(x i)=\sum u_{x i} w_{x i}
$$

where ${ }^{w_{x 1,1}}$ is the score of attribute income (\#1) for candidate location $1,{ }_{x i}$ is the weight of the candidate location i.

By using this approach, we calculated all candidates and official future housing plan locations in Figure 2, we found that recent affordable housing is better to be located in the area of Houhu,Gutian, Qingshan, Changqing, Sixin, Baishazhou and Zhanjiaji areas because these locations have high sorting results. In the long-term, other locations in Figure 2 can be scheduled step by step. 


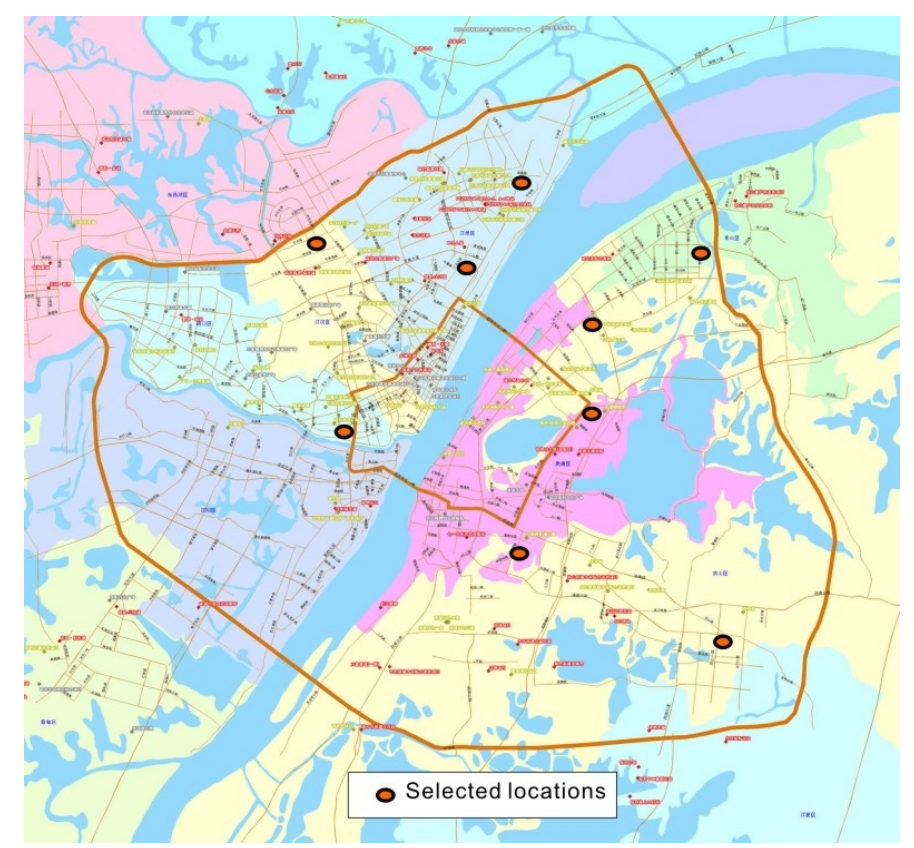

Figure 2. The official housing plan locations of Wuhan city:

\section{Building layout design and function analysis}

Although the sandwich class is belonging to low-income class or a little bit beyond the low-income class, they also have some different characteristics[15, 16], for example, most of them are usually graduated university students and off-farm workers. The graduated university students and off-form workers have different living taste and requirements. The design of building layout for them should meet the requirements of income, function and psychology. Usually, the area for these low-income class is about $40 \mathrm{~m} 2$. After the investigation of the layout by government, the layout design lack some functions, mismatch the function requirements and the same area of layout design cannot meet the requirements of families with different population structure, the population change cycle.
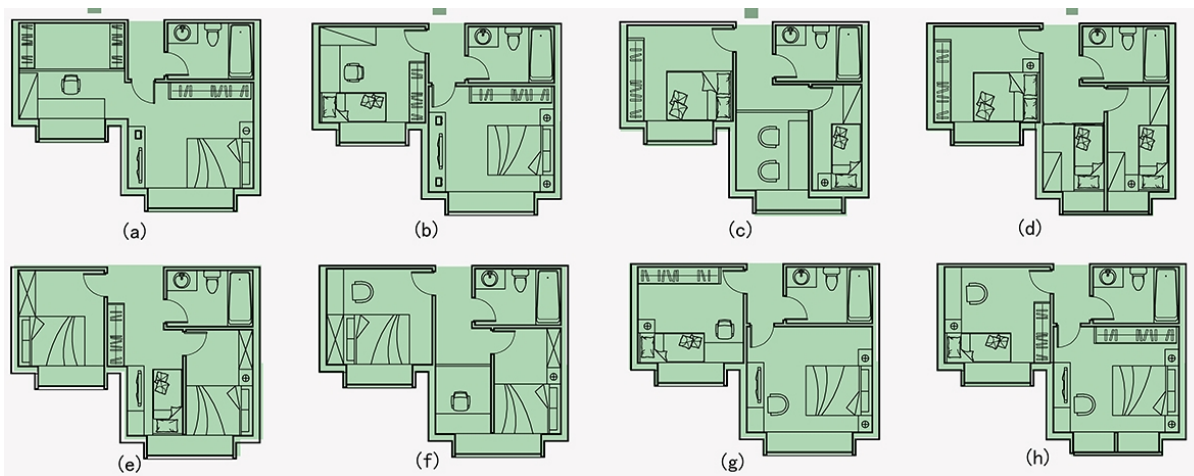

Figure 3. Building layout designs

(1) Diverse layout design

Sandwich class include graduated university students, some of them are married, some of them are new-coming off-farm workers. Diverse population means the building layout cannot be universal or identical each other. Diverse layout design can provide much more change of attracting these sandwich class people. For example, some of them think these housings are temporary living place. They can prefer some ignorance of function for low rentals, for instance, the orientation of buildings, or they can co-rent an apartment to sharing the rentals. Some other people who are married or plan to have new-born baby hope to have a community environment, and they usually want to choose a large area apartment for meet the requirement of parents' living and children's living. They can pay more rentals. Therefore, the building layout design should contains multi-type layout for diverse people, 
and balance the requirements of these diverse people. For example, the layout plan (a)-(c) in Figure 3 are likely the diverse layout design.

\section{(2)Changeable layout design}

Changeable layout design means the housing structure or space forms can be changed according to the people's diverse requirements. During the design, we can place some changeable spaces within the layout to improve the flexibility of room use. For example, different uses can change the room functions according to these needs. These changeable space can be decided by the uncertainty of living behaviors, different family may have different living space needs even they live a same layout building. User can schedule the use of a space in different time and schedule the room use functions. For example, a room can be used as reading room or tea room, it also can be used as baby room, making up room or storage room. If their relatives visit his house, these rooms can be used a temporary bedroom. Another example is that some young people want to live with their parents and children, they want to divide room spaces into different parts. For example, the layout plan (d)-(f) in Figure 3 are the changeable layout design.

\section{(3)Detailed layout design}

Public housing for sandwich class is small bout the detailed of layout should be reasonable, is still can be "small but perfectly formed", which can balance the function and practice spaces. Sandwich class also concerns the detailed design and quality of the building layout. They can pay much attention on the furniture design. If these young people love to take party, they can fold the bed to reserve more spaces for living. If they do not have reading room, they prefer to read on computer on the bedroom, the next possible room is living room. The reading room and living room can be integrated into together for a whole design. For example, they can design a reading corner in the bedroom, folded table can also be placed on bed. Besides the bedroom, the dining room can also be designed as integrated space, for instance, the dining table can be also designed as the bar table. Due the area limit, the restroom is usually small, but it can also be divided into wet and dry areas. They can also design some embedded cabinets in wall which can store clothing and so on. For example, the layout plan (d)-(f) in Figure 3 are the detailed layout design.

\section{Conclusion and future work}

Sandwich class housing problem is very important for a harmonious society in China. The location and the building layout are two important questions for local government to make scientific decisions on building public housing. This paper proposed a locating approach of sandwich class housing through analytic hierarchy process method, which considers the influence of income, distance, time total money cost, school, hospital, store, neighborhood on the choosing of housing locations. As result, 9 candidate locations were chosen as the housing location for sandwich class in Wuhan city. Also, this paper presents some building layout design plans for meeting the needs of sandwich class livings. They can be categorized as diverse, changeable and detailed layout designs. The feature and satisfied functions of these categories were discussed in this paper. Both works can provide a suggestion for local government to make decisions of building public housing for sandwich class. In the future, we will continue to introduce the economy factors into the decision of analytic hierarchy process, and simulate the influence of optimized results on the choosing behavior, and will conduct some survey to evaluate the effectiveness of the proposed approach.

\section{Acknowledgment}

The research was supported by Excellent Young Teachers Program of Wuhan University of Science and Technology (Grants \#2012XZ020), the Science-Technology Foundation for Young Scientist of Hubei Province, China (Grants \#Q20131101) and Social Science Research Foundation for Young Scientist of Hubei Province, China(Grants \#14Q020). 


\section{References}

[1] R. L. H. Chiu, Social equity in housing in the hong kong special administrative region: a social sustainability perspective, Sustainable Dev., 10(2002) 155-162.

[2] Q. Ying, D. Luo, J. Chen, The determinants of homeownership affordability among the 'sandwich class' empirical findings from Guangzhou, China. Urban Studies, 50(2013).

[3] J. Peng, A survey of public rental housing research, J. Henan Unviers. of Urban Construct., 21(2012)78-82.

[4] D. Chen, Y. Wang, H. Chen, Z. Shi, C. Peng, Y. Chen, The research about the housing problem of 'sandwich layer' in Fuzhou, Fujian Archi. \& Const. 181 (2013) 98-100.

[5] J. LIU, Discussion on house type plane refining of public rental housing, Shanxi Architecture, $39(2013) 17-19$.

[6] A.Wang, Research on Queuing evaculation of public rental housing based on the improved vague-topsis method, J. Zhengzhou Unviers. (Natural Science Edition), 45(2013) 34-38.

[7] Y.Zhou, J.Lin, Exploration and suggestion about relevant policies for construction of beijing public rental housing. Architecture Journal, 4(2013) 51-56.

[8] V. Nebbitt, M. Lombe, C. Lavelleamckay, A. Sinha, correlates of academic performance among school-age african american males in public housing. Child Youth Serv Rev, 44(2014) 65-71.

[9] E.K. Anthony, D.E. Robbins, A latent class analysis of resillent development among early adolescents living in public housing, Child Youth Serv Rev, 35(2013) 82-90.

[10]C.E. Pollack, A. Kennedy-Hendricks, H. Green, D. Kennedy, B.A. Griffin, S. Burkhauser, etc. The impact of public housing on social networks: A natural experiment. Am J Public Health, 104(2014)1642-1649.

[11]T. Leech, Subsidized housing, public housing and adolescent violence and substance uses, YOUTH SOC, 44(2012) 217-235.

[12] S. Burgos, P. Ruiz, R. Koifman, Changes to indoor air quality as a result of relocating families from slums to public housing. Atomes Environ, 70(2013)179-185.

[13]P. Groselj, L. Strim, Acceptable consistency of aggregated comparison matrices in analytic hierarchy process, Eur J Oper Res , 223(2012) 417-420.

[14]B. Zhu, Z. Xu. Analytic hierarchy process-hesitant group decision making. Eur J Oper Res, 239(2014) 794-801.

[15]J.Dong, H.Jin, The design strategy of green rural housing of Tibetan areas in Yunan, China. Renew energ, 49(2013)63-67.

[16]Y. Yau, Ruling out trouble: unacceptable behaviour and its control in Hong Kong's public housing, Habitate International, 36(2012)11-19. 